\title{
Surgical treatment of false aneurysm of the left ventricle after myocardial infarction
}

\author{
FP SHABBO, DS DYMOND, GM REES, IM HILL \\ From the Department of Cardiothoracic Surgery, St Bartholomew's Hospital, London
}

\begin{abstract}
Rupture of the left ventricle after myocardial infarction results either in sudden death from cardiac tamponade or, when pericardial adhesions are present, in bleeding that is confined to a limited space, which gradually expands as the blood flows through a small communicating orifice under high pressure, forming a false aneurysm. In three such patients a false aneurysm of the left ventricle after myocardial infarction was successfully treated by operation. The interval from the initiating event to the time of surgery averaged 10 months. Two of the patients had pericarditis and all presented at some stage of the illness with tachyarrhythmias and cardiac failure. All the patients survived operation and have improved functionally. Because of the propensity of false aneurysms to rupture, early diagnosis and aggressive surgical treatment are recommended.
\end{abstract}

Rupture of the heart as a complication of acute myocardial infarction is responsible for $5-13 \%$ of deaths after infarction..$^{1-3}$ While the incidence of true ventricular aneurysm after infarction is about $10 \%,{ }^{4}$ the incidence of false aneurysm is not known. False aneurysms are characterised by the presence of a narrow neck and a wall containing fibrous tissue and laminated clot but no myocardial elements and they have a strong tendency to rupture. ${ }^{5}$ By contrast, the true aneurysm has a wide neck and its wall is formed by scattered myocardial elements.

In the published reports there have been several cases of sudden death either from rupture of the false aneurysm or from irreversible tachyarrhythmias and cardiac failure. ${ }^{6-8}$ Early diagnosis and treatment is therefore essential. Diagnosis and assessment are based on the clinical presentation and the results of echocardiography, ${ }^{9-11}$ first-pass radionuclide ventriculography, ${ }^{12}$ radioisotope imaging, ${ }^{13}$ and cardiac catheterisation. ${ }^{14-16} \mathrm{We}$ report the clinical features, an evaluation of the diagnostic procedures, and the surgical management of three successfully treated cases.

\section{Case reports}

PATIENT 1

A 63-year-old man, who had inferior myocardial infarction in June 1976, was admitted with shortness

Address for reprint requests: Mr IM Hill, Cardiothoracic Department, St Bartholomew's Hospital, West Smithfield, London $\mathrm{EC} 17 \mathrm{BE}$. of breath, frothy sputurn, and recent mild chest pain. He was febrile $\left(38.5^{\circ} \mathrm{C}\right)$, with atrial fibrillation, cardiac failure, and a pericardial friction rub. His electrocardiogram showed $Q$ waves and ST elevation in leads II, III, and AVF. His cardiac enzyme levels were raised and his erythrocyte sedimentation rate was $67 \mathrm{~mm}$ in one hour. His chest radiograph showed cardiomegaly with a bulge over the inferior surface of the heart, displacing the apex upwards and laterally (fig 1). A diagnosis of inferior myocardial infarction with pericarditis was made, with the possibility of an inferior left ventricular aneurysm. He was treated with digoxin, frusemide, and steroids and made a good recovery; but he declined the offer of further investigation and was discharged.

He was readmitted three months later with a brief episode of confusion associated with numbness over the left side of his face. A diagnosis of cerebral embolus from a left ventricular aneurysm was made and he was given anticoagulant treatment. First-pass radionuclide ventriculography, using a multicrystal gamma camera with bolus intravenous injection of technetium $-99 \mathrm{~m}$ as pertechnetate, showed a left ventricular ejection fraction of $38 \%$ and a large aneurysmal sac attached to the inferior surface of the left ventricle (fig 2), which expanded paradoxically in systole. Cardiac catheterisation and left ventricular cineangiography confirmed these findings (fig 3). Coronary angiography showed a completely occluded right coronary artery with a normal left system.

At operation in December 1977 he was found to 


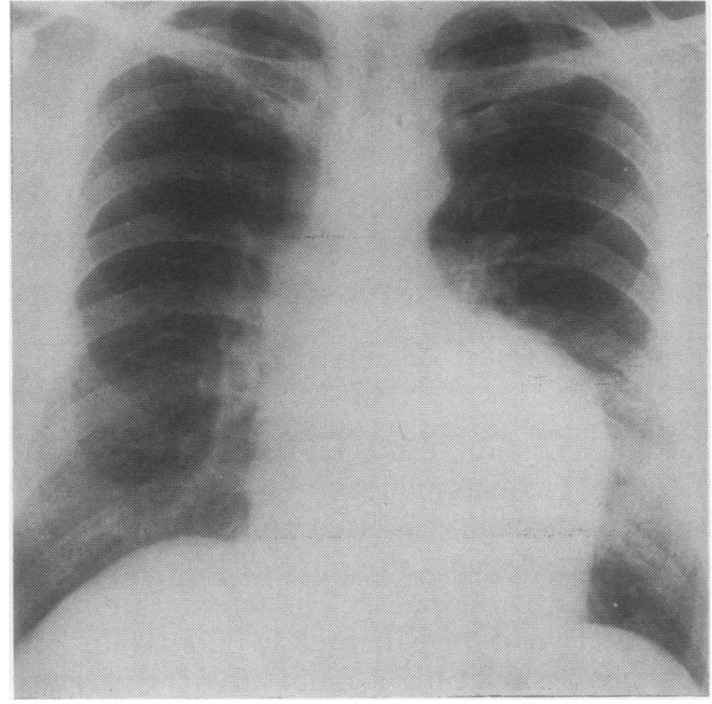

Fig 1 Patient 1: posteroanterior chest radiograph showing an inferior left ventricular bulge displacing the apex of the heart upward and laterally.
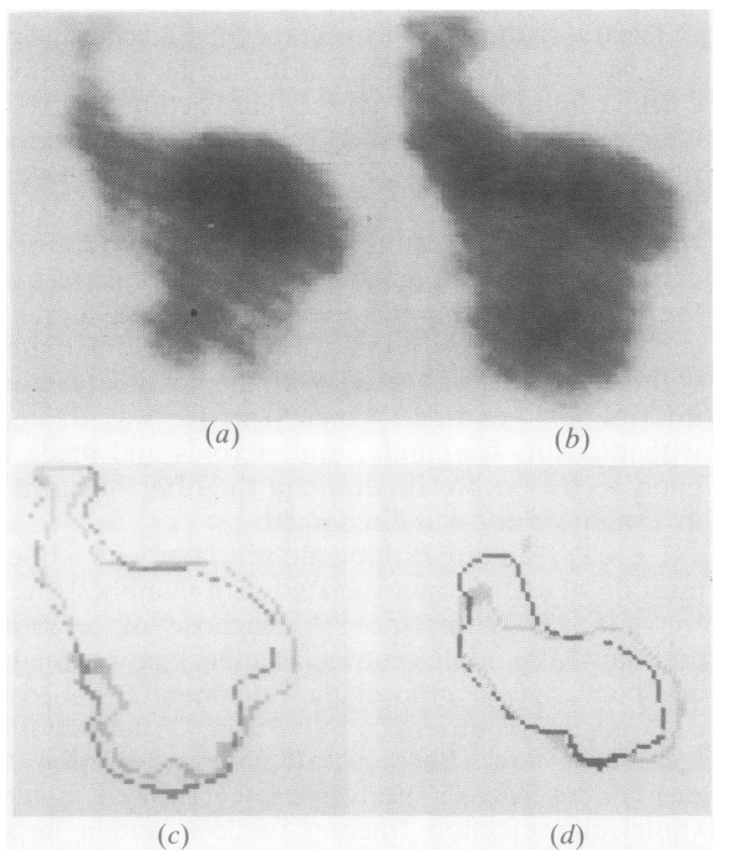

Fig 2 Patient 1: radionuclide ventriculogram, in the right anterior oblique position (a) in diastole and (b) in systole, showing paradoxical expansion of an inferior left ventricular aneurysm in systole; (c) superimposed preoperative perimeter, end-systole (dark) and end-diastole (light), showing the paradoxical expansion of the aneurysmal sac in systole; (d) postoperative perimeter showing no aneurysmal sac but an akinetic inferior wall.

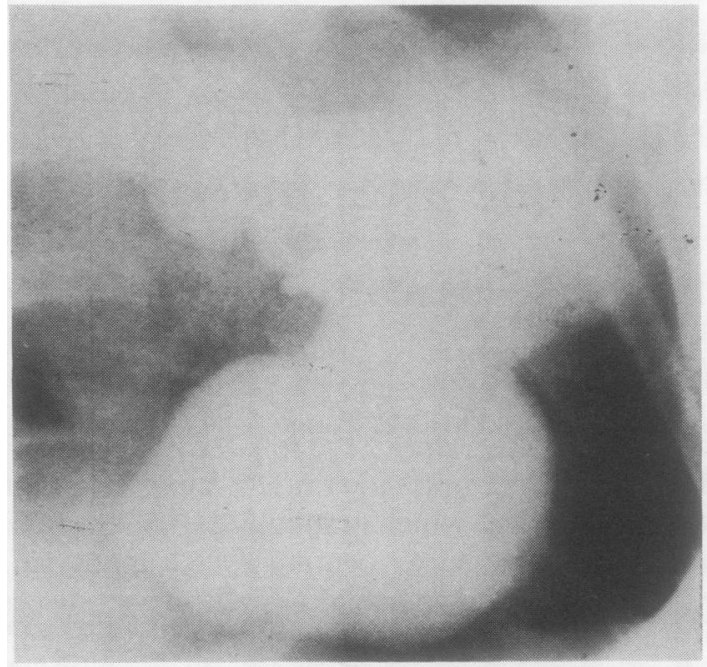

Fig 3 Patient 1: left ventricular cineangiogram, in the right anterior oblique position in systole, showing a false inferior left ventricular aneurysm with a narrow neck.

have widespread pericardial adhesions, which were dense over a large inferior aneurysmal mass. The wall of the aneurysm was thin and lined by a laminated thrombus and fresh thrombus. The communicating defect measured $3 \times 1 \mathrm{~cm}$ (fig 4 ) and had a thickened fibrous margin. This was closed with prolene sutures reinforced by two pieces of teflon felt. The wall of the aneurysm was partially resected. His postoperative recovery was uneventful and a radionuclide study before his discharge showed an akinetic inferior surface with no change in the ejection fraction (fig 2). Forty-two months later he was symptom free and leading a fairly active life.

\section{PATIENT 2}

A 57-year-old man was well until November 1979, when he was admitted to hospital after collapsing on a dance floor with upper abdominal pain. He had no past history of ischaemic heart disease. He was obese and orthopnoeic, with a pulse rate of 130 beats $/ \mathrm{min}$ and no air entry to the left side of his chest. An ECG $\sigma$ showed $Q$ waves in leads I and AVL and T inversion $N$ in leads III, II, AVF and V4-V6. A chest radiograph ్ㅗ showed a completely opaque left chest. His haemoglobin concentration was $8.5 \mathrm{~g} / \mathrm{dl}$. Needle aspiration showed a left haemothorax. Left thoracotomy was performed but there was no evidence of pulmonary disease or aortic dissection. When the pericardium was opened it was obvious that the patient had had a myocardial rupture over the posterolateral aspect of the left ventricle; this was small and had sealed spontaneously. The patien 


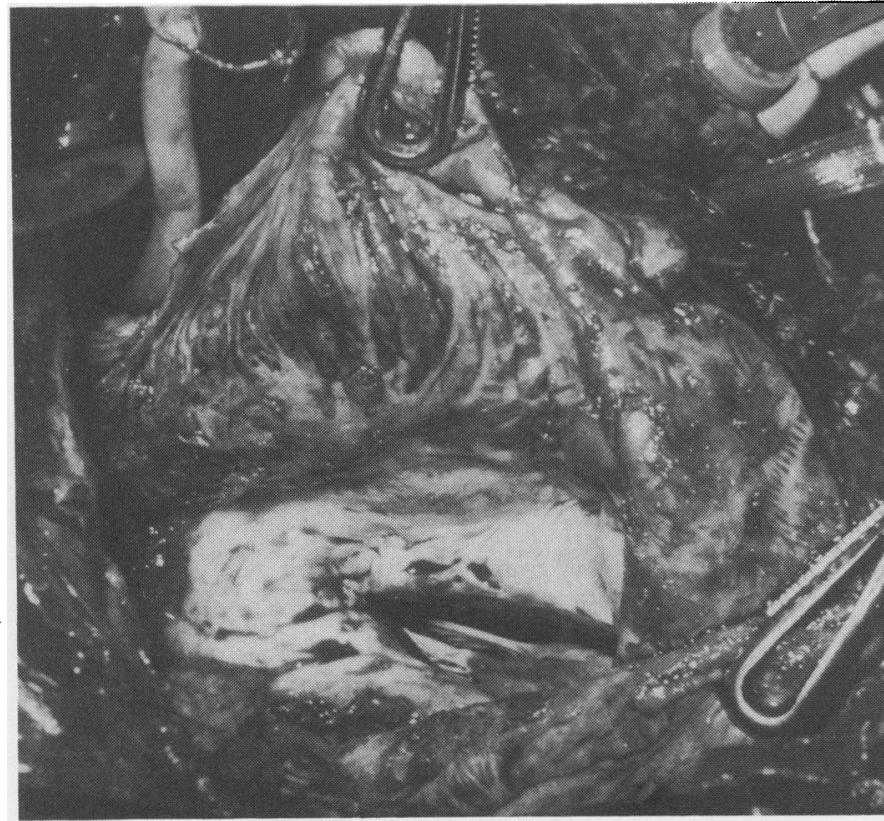

Fig 4 Patient 1: operative photograph showing the false aneurysmal wall with a communicating orifice into the left ventricle.

made a good postoperative recovery, and was discharged taking anticoagulants. Three months later his chest radiograph showed cardiomegaly and a firstpass radionuclide ventriculogram showed an ejection fraction of $61 \%$ with a suspicious paradoxical segment over the lateral wall of the left ventricle. He was readmitted two months later in cardiac failure with a tachycardia due to 2:1 flutter. The ECG showed old lateral infarction with ST elevation in leads V3-V6 and AVL. A further chest radiograph showed cardiomegaly with a bulge over the lateral border of the heart. Cardiac catheterisation showed a large posterolateral ventricular aneurysm communicating with the left ventricle by a small neck. Coronary angiography indicated severe stenosis in a large marginal branch of the circumflex artery and irregularity in the anterior descending artery.

At operation in June 1980 there were dense adhesions and a large posterolateral left ventricular aneurysm just below the atrioventricular groove. The wall of the aneurysm was thin and fibrotic and contained no clots. The communicating orifice measured $2 \times 4 \mathrm{~cm}$ and had a thick fibrous edge. This was oversewn with prolene sutures and reinforced with two pieces of teflon felt. The patient made a good recovery. He was symptom free and leading an active life 12 months later.

\section{PATIENT 3}

A 64-year-old woman was admitted to hospital in December 1980 with anterolateral myocardial infarction. She was readmitted three weeks after discharge in congestive heart failure with a tachycardia and pericarditis. She was treated with bed rest, frusemide, spironolactone, and steroids. She made a good recovery and was discharged taking only diuretics.

Three months later she was readmitted for investigation of progressive shortness of breath. Her chest radiograph showed cardiomegaly with a bulge over the lateral border of the heart (fig 5). The ECG showed persistent ST elevation in leads I, AVL and V4-V6. First-pass radionuclide ventriculography showed an ejection fraction of $18 \%$ with a large left ventricular aneurysmal sac over the lateral wall of the ventricle (fig 6), which moved paradoxically in systole. Cardiac catheterisation again confirmed the findings (fig 7). Coronary angiography showed a completely occluded left anterior descending artery with minor irregularity in its diagonal branch and normal right and circumflex vessels.

At operation in July 1981 there were adhesions that were dense over the aneurysm. The aneurysmal wall was thin and fibrotic and contained laminated and fresh clot. The communicating orifice was $2 \times 3 \mathrm{~cm}$ and had a thick fibrous edge in the lateral wall of the left ventricle. This was oversewn with prolene and reinforced with two pieces of teflon felt. The wall of the aneurysmal sac was partially excised. The patient made a good recovery. A postoperative radionuclide study showed an ejection fraction of $29 \%$ with an akinetic anterior wall and apex and normal inferior wall motion (fig 6). The patient was symptom free and leading a fairly active life six months later. 


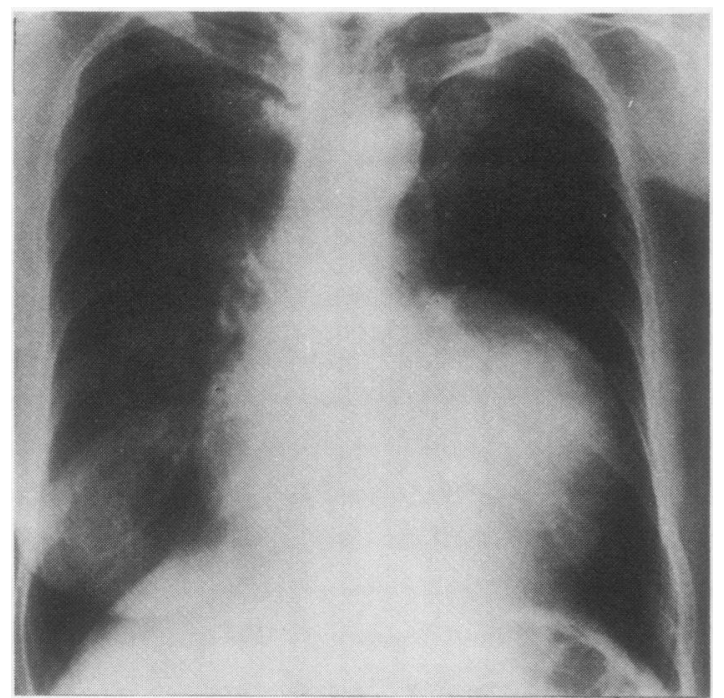

Fig 5 Patient 3: posteroanterior chest radiograph showing a bulge over the lateral border of the left ventricle.

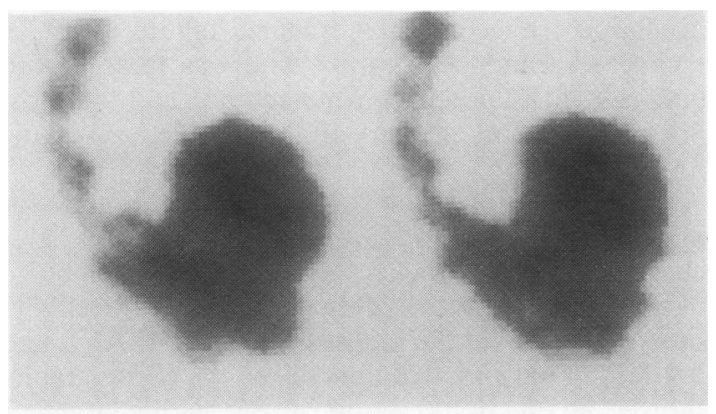

(a)

(b)

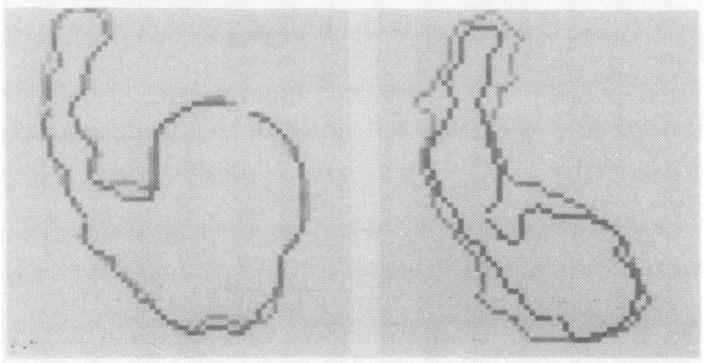

(c)

(d)

Fig 6 Patient 3: radionuclide ventriculogram, in the right anterior oblique position (a) in systole and (b) in diastole, showing a large anterolateral ventricular aneurysm with some paradoxical expansion in systole; (c) superimposed preoperative perimeter, end-systole (dark), end-diastole (light); (d) postoperative perimeter showing no evidence of an aneurysmal sac, but an akinetic anterior wall and apex.

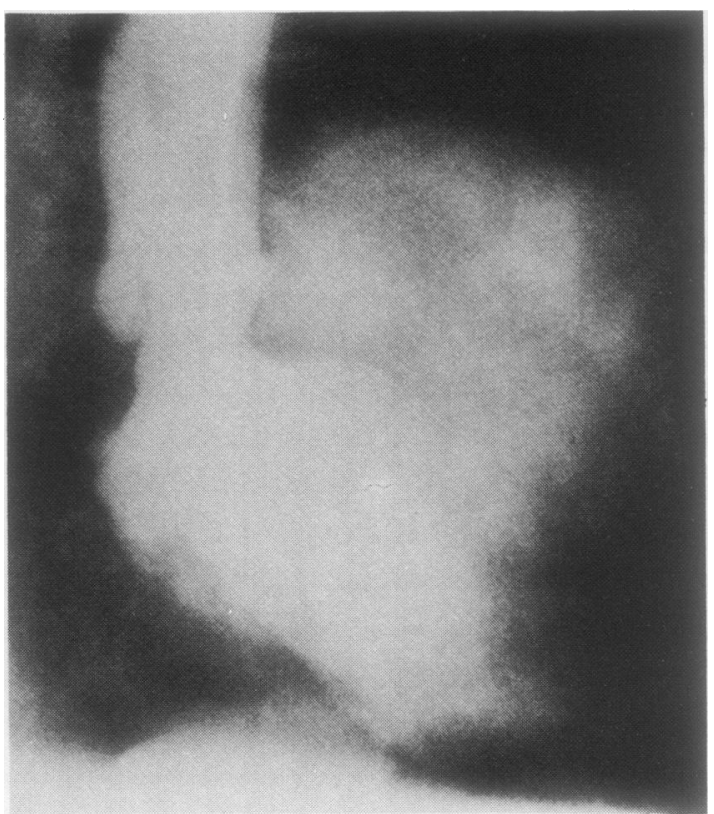

Fig 7 Patient 3: left ventricular cineangiogram, in the right anterior oblique position in systole, showing a large anterolateral left ventricular aneurysm.

\section{Discussion}

False aneurysm of the left ventricle after myocardial infarction is rare, in contrast to true aneurysm. Rupture of the heart occurs after a haemorrhagic dissection into a zone of transmural infarction. Either this results in death from cardiac tamponade or, if the overlying pericardium is adherent to the surface of the heart, the haematoma dissects through the myocardium and is confined within the adherent pericardium. ${ }^{17}$ The left ventricular pressure is then transmitted through the tract into the pericardium, forming an expansile false aneurysm. The wall of the aneurysm is formed from pericardium overlying dense fibrous tissue, with no myocardial elements. The neck of the aneurysm is small compared with the fundus and the junction of the aneurysm with the left ventricular wall shows sudden interruption of the myocardial tissue. ${ }^{6}$ Organised thrombus usually forms part of the aneurysmal wall. This was found in two of our cases but not in patient 2 , as he was having adequate anticoagulant treatment from the time of his myocardial infarction. The true left ventricular aneurysm forms part of the left ventricle, its wall contains myocardial elements, and the diameter of the communicating orifice is usually the largest diameter of the aneurysm.

In a review of published reports we found only 56 
cases of postinfarction false left ventricular aneurysms. Thirty-five patients underwent surgical treatment with a mortality of $20 \%$ (seven deaths), while patients who were not surgically treated all died either from rupture or from cardiac arrhythmias and cardiac failure. Rupture of the false aneurysm was the cause of death in four of the nine patients reported by Van Tassel and Edwards ${ }^{6}$ and in nine of the 31 patients reviewed by Davidson. ${ }^{11}$ Over two-thirds of the patients who were treated surgically had their operation within the first 12 months after myocardial infarction and only three patients had their surgery after an interval of three years. ${ }^{18-20}$ Two of our patients had their operations at seven months and one at 18 months from the time of their infarction.

Thromboembolism from the wall of the aneurysm occurred in nine of the 31 patients reported by Davidson $^{11}$ and in one of our three patients. This is a lower incidence than is seen with true ventricular aneurysms and may be due to the narrow neck of the false aneurysm.

The surgical management of false aneurysms is simpler than that of true aneurysms, as no excision of the left ventricular wall is required because the aneurysm does not form part of the functional left ventricular wall. All our operations were performed with cardiopulmonary bypass, moderate hypothermia, and root cardioplegia.

The clinical presentation of the patient is of value in making the diagnosis. In the 56 patients reviewed, pericarditis with persistent ST elevation was seen in half and cardiac failure was present in most, with or without supraventricular tachyarrhythmias. The chest radiograph is also helpful; it showed cardiomegaly with abnormal bulges from the ventricular wall in all our patients. The echocardiogram is of diagnostic value, as reported by Davidson," Roelandt, ${ }^{9}$ and Gatewood and Nanda, ${ }^{10}$ who also confirmed that differentiation between false and true left ventricular aneurysms could be achieved with the use of two-dimensional echocardiography. ${ }^{10}$ First-pass radionuclide ventriculography in the right oblique position is non-invasive and proved to be diagnostic in our patients. It estimates the ejection fraction accurately and identifies the aneurysmal chamber attached to the wall of the left ventricle. It also shows the paradoxical systolic expansion of the aneurysm and obliteration of the aneurysm after surgery. Angiography will also determine whether an aneurysm is true or false and in addition will show whether there is appreciable coronary artery disease or mitral regurgitation that might require additional surgical treatment.

In view of the fatal complications of false left ventricular aneurysm, non-invasive procedures such as echocardiography and radionuclide ventricul- ography are valuable in evaluating patients with cardiomegaly, cardiac failure, and electrocardiographic changes suggestive of aneurysm formation after myocardial infarction. For the same reason an aggressive surgical approach is also indicated.

\section{References}

' Friedman S, White PD. Rupture of the heart in myocardial infarction: experience in large general hospital. Ann Intern Med 1944;21:778-82.

${ }^{2}$ London RE, London SB. Rupture of the heart, a critical analysis of 47 consecutive autopsy cases. Circulation 1965;31:202-8.

${ }^{3}$ Griffith GC, Hedge G, Oblath RW. Factors in myocardial rupture, an analysis of 204 cases at Los Angeles County Hospital between 1924 and 1959. Am J Cardiol 1961;8:792-8.

4 Abrams DL, Edlelist A, Luria MD, Miller AJ. Ventricular aneurysm. Circulation 1963;27:164-9.

5 Vlodaver Z, Coe JI, Edwards JE. True and false left ventricular aneurysm: propensity for latter to rupture. Circulation 1975;51:567-72.

- Van Tassel RA, Edwards JE. Rupture of heart complicating myocardial infarction. Chest 1972;61: 104-16.

${ }^{7}$ Ersek RA, Chesler E, Korns ME, Edwards JE. Spontaneous rupture of false left ventricular aneurysm following myocardial infarction. Am Heart J 1969;77:677-80.

${ }^{8}$ Chesler E, Korns ME, Semba T, Edwards JE. False aneurysm of the left ventricle following myocardial infarction. Am J Cardiol 1969;23:76-82.

${ }^{9}$ Roelandt J, Brand MV, Vletter WB, Nanta J, Hugonholtz PG. Echocardiogram diagnosis of pseudo aneurysm of the left ventricle. Circulation 1975;52: 466-72.

${ }^{10}$ Gatewood RP, Nanda NC. Differentiation of left ventricular pseudo aneurysm from true aneurysm with two dimensional echo-cardiography. Am J Cardiol 1980;46:869-77.

" Davidson KH, Parisi AF, Harrington JJ, Barsamian EM. Fishbein MC. Pseudo aneurysm of the left ventricle, an unusual echocardiographic presentation: review of the literature. Ann Intern Med 1977;86:430-3.

12 Dymond DS, Elliot AT, Banim S. Detection of false left ventricular aneurysm by first pass radionuclide ventriculography. J Nucl Med 1979;20:851-4.

${ }^{13}$ Botvinick EH, Shames D, Hutchinson JE, et al. Noninvasive diagnosis of false left ventricular aneurysm with radioisotope gated cardiac blood pool imaging: differentiation from true aneurysm. Am J Cardiol 1976;37:1089-93.

${ }^{14}$ Gueron M, Hirsch M, Venderman K, et al. Pseudoaneurysm of the left ventricle: report of a case diagnosed by angiography and successfully repaired. Br Heart J 1973;35:663-5.

is Smith RC, Goldberg H, Baily CP. Pseudo-aneurysm of the left ventricle: diagnosis by direct cardio angiography. Surgery 1957;42:496-570.

${ }^{16}$ Swanson A, Liu CM, Alexander CS, Kieffer SA. 
Posterior left ventricular pseudo-aneurysm: angiographic and pathologic correlation. Radiography 1973;106:275-6.

${ }^{17}$ Stewart S, Huddle R, Stuard I, Schriener BF, Deweese JA. False aneurysm and pseudo-false aneurysm of the left ventricle: etiology, pathology and operative management. Ann Thorac Surg 1981;31:259-65.

18 Roberts WC, Marcow AJ. Pseudo-aneurysm of the left ventricle: an unusual sequel of myocardial intarction $\stackrel{x}{.}$ and rupture of the heart. Am J Med 1967;43:639-44.

${ }^{19}$ Harper RW, Sloman G, Westlake G. Successful surgical resection of chronic false aneurysm of the left ventricle. Chest 1975;67:359-61.

${ }^{20}$ Buehler DL, Stinson EB, Dyer PE, Shumway NE. Surgical treatment of aneurysms of the inferior left $\mathbb{D}$ ventricular wall. J Thorac Cardiovasc Surg 1979;78:748. 